Coleman et al., 2018 - How, where, and when do radial faults grow near salt diapirs? https://doi.org/10.1130/G40338.1

\title{
1 How, where, and when do radial faults grow near salt diapirs?
}

3 Alexander J. Coleman ${ }^{1}$, Christopher A.-L. Jackson'1, Oliver B. Duffy ${ }^{2}$, and Maria A.

$4 \quad$ Nikolinakou ${ }^{2}$

5

$6{ }^{1}$ Basins Research Group (BRG), Department of Earth Science and Engineering, Imperial College,

$7 \quad$ Prince Consort Road, London SW7 2BP, UK

$8{ }^{2}$ Bureau of Economic Geology, The University of Texas at Austin, University Station, Box X, $9 \quad$ Austin, Texas 78713-7508, USA

10 *E-mail: a.coleman14@imperial.ac.uk

\section{ABSTRACT} determine how, where, and when radial faults grow near a salt diapir. We show roof stretching

15 alone cannot account for the large heights and lengths of the kilometer-scale radial faults, suggesting stock widening ('stem push'), a mechanism implied in numerical models but not yet recognized in natural examples, played a pivotal role in fault formation. We suggest that, when a diapir is covered by a roof, radial faults form due to roof stretching, extending no further than the limit of the drape folding. The roof may then be shouldered aside and the faults buried along the stock flanks, exposing these strata to stem push-related stresses that may then re-activate preexisting, or form new, radial faults. We suggest the causal mechanism for radial fault formation

22 will likely change as roof thickness varies during diapirism, with this reflecting the ratio between sedimentation rate and salt volumetric flux. 
Coleman et al., 2018 - How, where, and when do radial faults grow near salt diapirs? https://doi.org/10.1130/G40338.1

\section{INTRODUCTION}

Sub-circular salt diapirs or 'stocks' are ubiquitous in salt-bearing sedimentary basins, and are typically associated with complex fault networks in surrounding country rock. The most common fault networks comprise 'radial faults' (i.e., normal faults that extend radially from a stock into flanking strata). Radial faults may control the migration of crustal fluids (e.g., Davison et al., 2000a), may compartmentalize hydrocarbon reservoirs (e.g., Carruthers et al., 2013), and may provide a relatively high-fidelity record of the evolving near-salt stress conditions associated with salt diapirism (cf. Quintà et al., 2012; Nikolinakou et al., 2014).

Despite being widespread, and geologically and economically important, the origin of radial faults remains unclear. Radial faults in unpierced roofs above rising stocks are undoubtedly related to outer-arc extension during active rise ('roof stretching'; Fig. 1A). Roof stretchingrelated radial faults may nucleate anywhere in, but not necessarily extend fully across, the arched overburden (Withjack and Scheiner, 1982). As a stock pierces its overburden, roof radial faults may be eroded or shouldered aside, and buried along the stock flanks (e.g., Carruthers et al., 2013). Stretching and shouldering aside of the roof may occur during 'drape folding' during passive diapirism (Giles and Rowan, 2012) or regional extension, or alternatively during active rise driven by regional shortening (Dooley et al., 2009; Jackson and Hudec, 2017).

Radial faults may also form due to a widening stock pushing outward against its flanking strata (e.g., Bishop, 1978; Nikolinakou et al., 2014, their figure 7), herein termed 'stem push' (Fig. 1B). Stem push-related radial faults form at the salt-sediment interface where circumferential stretching is greatest and the horizontal stresses are anisotropic. Although numerical models suggest stem push is a plausible mechanism to form radial faults (e.g., Nikolinakou et al., 2014), 
Coleman et al., 2018 - How, where, and when do radial faults grow near salt diapirs? https://doi.org/10.1130/G40338.1

observations from a natural salt stock have never critically tested this prediction, nor characterized and quantified the associated strain.

Drape folding above a passively rising diapir is typically recorded by synkinematic Composite Halokinetic Sequences (CHS; Giles and Rowan, 2012), with two end-members recognized: tapered and tabular. Tapered CHS form when the salt is buried by a relatively thick roof, as sedimentation rate outpaces the volumetric flux of salt; in this case, broad, kilometer-scale drape folds form. Tabular CHS form when the salt is at, or very near, the surface and covered by only a relatively thin roof, and the volumetric flux of salt is greater or equal to the sedimentation rate (e.g., Giles and Rowan, 2012; Jackson and Hudec, 2017); in this case, narrow drape folds (< $200 \mathrm{~m}$ ) form next to the salt-sediment interface. As the roof is pierced, strata containing drape fold-related radial faults are either eroded or buried along with the contained faults along the flanks (Fig. 1A). In tapered CHS, radial faults are expected to extend greater distances $(<1000 \mathrm{~m})$ from the salt due to broader folding compared to tabular CHS $(<200 \mathrm{~m})$. It follows that radial faults extending more than a few hundred meters laterally in tabular CHS must have formed due to stem push rather than roof stretching alone, although this has never been tested.

Here, we test these hypotheses by identifying CHS and applying quantitative fault analysis to infer where faults nucleated and how they grew around a salt stock imaged in three-dimensional (3-D) seismic reflection data from the Santos Basin, offshore Brazil (Fig. 1C). Using this approach, we: (1) link the genetic mechanism of radial fault formation to salt diapirism, and (2) for the first time using a natural example, test the validity of the stem push model, using exceptionally wellimaged radial faults flanking and overlying a salt stock. These data not only allow us to map radial fault-diapir relationships in 3-D and constrain their kinematics, but also investigate when, during diapirism, roof stretching and stem push may occur. 
Coleman et al., 2018 - How, where, and when do radial faults grow near salt diapirs? https://doi.org/10.1130/G40338.1

\section{DATASET AND METHODS}

We used $225 \mathrm{~km}^{2}$ of a $850 \mathrm{~km}^{2}$ Kirchhoff pre-stack time-migrated (PSTM), zero-phase processed, 3-D seismic data set. Inline and crossline spacing are $14 \mathrm{~m}$ and $25 \mathrm{~m}$, respectively. A frequency of $\sim 15-40 \mathrm{~Hz}$ and assumed average velocity of $\sim 2000 \mathrm{~m} / \mathrm{s}$ (after Jackson et al., 2014) yield an estimated vertical resolution of $\sim 12 \mathrm{~m}$ at shallow depths, decreasing to $\sim 35 \mathrm{~m}$ toward the base of supra-salt minibasins (see Appendix DR1 in the GSA Data Repository ${ }^{1}$ for details). All seismic data are displayed in milliseconds two-way time (ms TWT), but measurements are converted from time to depth using an interval velocity of $2000 \mathrm{~m} / \mathrm{s}$. We first mapped three seismic horizons $(\mathrm{H} 1-\mathrm{H} 3)$ to constrain salt body geometry, and the 3-D distribution of throw on, and kinematics of, individual faults (Appendix DR2). Quantitative fault analysis was not undertaken for $\mathrm{H} 1$ because throw was at the limit of seismic resolution (i.e., <25 m; Appendix DR3). We then identified nine Late Cretaceous-Tertiary stratigraphic units adjacent to the stock, assigning them to the two end-member CHS styles of Giles and Rowan (2012) based on the width of folding and thinning and the geometry (convergent or parallel) of the bounding unconformities. These CHS allowed us to interpret periods when the rising diapir was buried by a thick (tapered CHS) or thin (tabular CHS) roof (Fig. 2) (see Giles and Rowan [2012] for recognition criteria). We then grouped the units into three packages based on CHS style, and whether the stock had pierced strata at the level of observation. Package A consists of tabular CHS, whereas packages B and C contain tapered CHS. Packages A and B have been pierced by the salt, whereas C has not. H1 lies in package $\mathrm{A}, \mathrm{H} 2$ at the boundary between packages $\mathrm{A}$ and $\mathrm{B}$, and $\mathrm{H} 3$ in package $\mathrm{C}$. 
Coleman et al., 2018 - How, where, and when do radial faults grow near salt diapirs? https://doi.org/10.1130/G40338.1

\section{GEOLOGICAL SETTING}

The Santos Basin formed during Early Cretaceous rifting and initial opening of the South Atlantic, during which time a thick Aptian salt layer was deposited (Ariri Formation) (Mohriak et al., 2008; Contreras et al., 2010). Subsequent deposition of Albian (carbonate-dominated) and Cenomanian-Holocene (siliciclastic-dominated) rocks, in addition to thin-skinned gravity-driven extension, drove seaward salt flow and diapir growth (Demercian et al., 1993; Modica and Brush, 2004; Davison et al., 2012). We focus on a salt stock located (Fig. 1C) in the proximal, extensional domain (after Davison et al., 2012), in an area unlikely to have undergone Albian shortening. Like many salt structures in this area, the stock initiated as a reactive diapir, before undergoing passive and active rise driven by sediment loading (Jackson et al., 2015). Here, we focus only on the latter stages of diapirism once the stock had developed, where CHS and radial faults formed.

\section{SALT STOCK AND OVERBURDEN GEOMETRY, AND DIAPIRISM}

The salt stock is expressed in seismic data as a package of chaotic, low-amplitude reflections. In cross section, the stock is $\sim 4 \mathrm{~km}$ tall and has a 'finger' geometry, consisting of a $<2.3$-km-wide smooth head and stem, and a <6-km-wide pedestal (Fig. 2). In plan view, the stock is sub-circular at shallow depths ( 2000 ms TWT) and oblate at greater depths ( 4000 ms TWT), with its long axis trending northeast. The presence of tabular CHS (with narrow drape folds $<200$ $\mathrm{m}$ from the salt) at deeper levels indicates that, following diapir initiation, the stock entered a protracted phase of passive diapirism when the volumetric flux of salt equaled or exceeded the background sedimentation rate (package A). Tapered CHS (with broad drape folds $<1000 \mathrm{~m}$ from the salt) dominate at shallower levels, suggesting that sedimentation rate outpaced the volumetric 
Coleman et al., 2018 - How, where, and when do radial faults grow near salt diapirs? https://doi.org/10.1130/G40338.1

112

113

114

115

116

117

118

119

120

121

122

123

124

125

126

127

128

129

130

131

132

133

134

flux of salt (packages B and C). This could reflect an increase in the regional sedimentation rate, or a decreased volumetric flux of salt as the source layer thinned and ultimately welded.

Shortening has been documented regionally in the Santos Basin (e.g., Demercian et al., 1993; Modica and Brush, 2004; Contreras et al., 2010). However, based on the stock's location in the extensional domain (after Davison et al., 2012), the sub-circular map-view geometry (cf. Jackson and Hudec, 2017), a lack of thrusts in the roof or flanking minibasins (cf. Davison et al., 2000b; Dooley et al., 2009), and fault patterns unlike those expected during compression (cf. Withjack and Scheiner, 1982), we interpret diapir growth was not driven by shortening. If shortening has occurred, the strains associated with this must be minimal (e.g., Davison et al., 2000a, 2000b).

\section{RADIAL FAULTS}

\section{Geometry and Distribution}

Radial faults are broadly linear in map view at all stratigraphic intervals (H1-H3), although they vary in their distribution, density, and length (Fig. 3). They occur over an $\sim 2.5 \mathrm{~km}$ depth range ( 1-3.5 km) within tapered and tabular CHS, although they tend to cluster around the stock head in tapered CHS (H2-H3). It is possible that radial faults exist but are not imaged at greater depths (>3.5 km). Faults are planar, 400-1400 m tall, have height-to-length aspect ratios of <2 (Appendix DR4), dip $50-60^{\circ}$, and have throws of $<80 \mathrm{~m}$. Faults occur in vertically stacked tiers. Faults in each tier have similar geometric characteristics; e.g., heights, lengths, and densities. Tier boundaries are undeformed, or at least deformation is sub-seismic. Tall radial faults, which are best-developed at shallower levels around the head of the stock in packages B and C, may crosscut several tier boundaries (Fig. 4; Appendix DR5). 
Coleman et al., 2018 - How, where, and when do radial faults grow near salt diapirs? https://doi.org/10.1130/G40338.1

\section{Throw Distribution}

We study the distribution of radial fault throw to determine where these structures nucleated with respect to the stock, which may reveal their formation mechanism. Throw maxima for faults offsetting $\mathrm{H} 2$ and $\mathrm{H} 3$ occur immediately at or some distance from the salt-sediment interface ( $<3 \mathrm{~km}$ from the salt; white squares in Fig. 3; Appendix DR6). Faults typically have ' $\mathrm{C}$ type' throw-depth profiles (sensu Muraoka and Kamata, 1983), with a throw maximum near their centers and very low gradients toward their tips $(<0.1)$ (Fig. 4A; Appendix DR7). Some faults may have several throw maxima separated by throw minima, and may offset presumably older, neighboring faults (Fig. 4B). Faults are not associated with growth strata (expansion indices of $\sim 1$;

Fig. 4), suggesting they were blind.

\section{Kinematics and Origin}

Based on their geometry, stratigraphic occurrence in tapered and tabular CHS, and throw distribution, we propose the radial faults have two origins. Radial faults developed in the roof and are contained in tapered CHS, with throw maxima (i.e., nucleation points; Muraoka and Kamata, 1983; Baudon and Cartwright, 2008) located both above and outboard of the stock, and do not intersect the salt, formed only due to roof stretching (H3 in Fig. 3; package $\mathrm{C}$ in Fig. 2). Predominantly NNW-SSE-striking faults, whose throw maxima occur outboard of the drape folding limit in $\mathrm{H} 3$ and do not encounter the salt, may reflect stresses related to diapir growth to the NNW and SSE, or movement of deeper-lying salt structures (Fig. 1C).

In contrast, radial faults in tabular CHS, and which are in contact with and extend several kilometers from the salt (that is, well beyond the limit of drape folding), formed due to stem push (H1 in Fig. 3; package A in Fig. 2). These faults nucleated at the salt-sediment interface where the circumferential extension is greatest (e.g., Nikolinakou et al., 2014; Jackson and Hudec, 2017). As 
Coleman et al., 2018 - How, where, and when do radial faults grow near salt diapirs? https://doi.org/10.1130/G40338.1

158

159

160

161

162

163

164

165

166

167

168

169

170

the stock was at or near the surface, with only a relatively thin roof during deposition of tabular CHS, radial faults associated with roof stretching would be limited to the relatively narrow extent of drape folding $(<200 \mathrm{~m})$, immediately adjacent to the stock. Roof stretching, therefore, cannot be responsible for the formation of radial faults that extend several kilometers away from the salt, now deeply buried in the stock flanks. Given that the majority of deep radial faults are not physically connected to shallow radial faults associated with roof stretching (Appendix DR5), the deep faults cannot be attributed to downward propagation of the shallower-level structures; they must therefore reflect a mechanism other than drape folding. The vertical extent of some radial faults was several kilometers (Fig. 4), again suggesting it is unlikely they formed due to roof stretching alone, as passive diapirs cannot arch kilometer-thick roofs (e.g., Davison et al., 2000b; Jackson and Hudec, 2017). Given the lack of evidence for regional shortening, a mechanism that could have lifted kilometer-thick diapir roofs and generated kilometer-tall faults, we propose such tall and laterally extensive faults grew due to stem push during passive diapirism.

Having considered radial faults in tabular CHS, we now explore which mechanism likely produced radial faults in package B (pierced tapered CHS). Radial faults in package B have their throw maxima either outboard of the salt or at the salt-sediment interface (H2 in Fig. 3). The former suggests roof stretching must have occurred over a broad region with discontinuous faulting; however, the latter could feasibly be explained by either: (1) stem push, or (2) roof stretching, and subsequent diapiric piercement of the overburden. In the first case, radial faults nucleate where circumferential extension is greatest due to stem push at the salt-sediment interface (Fig. 1B). In the second case, piercement of the overburden removes sections of the roof and portions of radial faults formed by roof stretching, thus truncating the original throw distribution. Throw maxima could therefore be only coincidentally located at the salt-sediment interface. Because the radial 
Coleman et al., 2018 - How, where, and when do radial faults grow near salt diapirs? https://doi.org/10.1130/G40338.1

181

182

183

184

185

186

187

188

189

190

191

192

193

194

195

196

197

198

199

200

201

202

203

faults were blind and were not associated with growth strata, we are unable to identify whether stem push re-activated preexisting roof stretching faults as the strata became buried (e.g., package B). Irrespective of their origin, radial faults grew, dip-linked, and offset preexisting radial faults beside the stock (Fig. 4B) (cf. Muraoka and Kamata, 1983; Baudon and Cartwright, 2008).

\section{DISCUSSION AND IMPLICATIONS}

By undertaking detailed mapping of 3-D seismic reflection data, we are able to not only better determine the full, 3-D geometry of in situ radial fault networks, but also constrain their kinematics. Based on our observations from the Santos Basin, we offer a genetic model that may be broadly applicable to other diapirs. We propose that, as a salt stock grows and roof thickness varies with changes in the volumetric flux of salt and/or sedimentation rate, it is likely that the mechanism responsible for forming radial faults will vary. Such changes in the relative balance of salt flux and sedimentation rate may, for example, reflect progressive welding of supra-salt minibasins, or changes in regional sedimentation rate.

Once passive diapirism occurs and a stock starts to grow, the volumetric flux of salt may outpace the background sedimentation rate, meaning the stock will be at or near the depositional surface, covered only by a relatively thin roof (i.e., tabular CHS). As this thin roof is arched and is shouldered aside by the rising diapir, roof stretching-related radial faults will be buried adjacent to $(<200 \mathrm{~m})$ the salt-sediment interface. As the source layer thins and the volumetric flux of salt decreases, the stock may be buried by a relatively thick roof (i.e., tapered CHS). Subsequent rise of the diapir generates stretching-related radial faults in the aggrading overburden, over a relatively broad area $(<1000 \mathrm{~m})$. Shouldering-aside and burial of the roof along the flanks (regardless of the CHS type) may expose these strata to stem push-related stresses, re-activating preexisting, or 
Coleman et al., 2018 - How, where, and when do radial faults grow near salt diapirs? https://doi.org/10.1130/G40338.1

204 forming new, radial faults. Faults in the vicinity of the salt may continue to grow throughout 205 diapirism, becoming taller and propagating laterally. Stem push-related re-activation of old faults 206 and the formation of new faults will likely be concentrated toward the upper parts of stocks where 207 the greatest stress perturbations occur (e.g., Nikolinakou et al., 2014, their figures 8 and 9). Finally, 208 as the salt supply is exhausted and minibasins weld, sedimentation rate may outpace the volumetric 209 flux of salt, causing stock burial (cf. Giles and Rowan, 2012; Jackson and Hudec, 2017). Once 210 diapirism ceases, no further radial faults form unless latter extension or shortening occurs. As the genetic mechanism for forming radial faults likely changes during diapirism, the 212 geometry and kinematics of those faults will likely change, especially where they have interacted 213 to create complex fault geometries. This could prove problematic when inverting fault network 214 geometry for paleostress conditions (cf. Quintà et al., 2012; Carruthers et al., 2013), leading to 215 questionable interpretations of salt diapir-related stresses, and the mode and distribution of 216 fractures around salt stocks. In addition, we highlight the structural variability and potential 217 reservoir compartmentalization that may occur around salt stocks, providing insights into areas 218 where radial faults are not exposed or are poorly imaged (e.g., Jones and Davison, 2014).

219 Finally, we note the Santos Basin radial faults are shorter ( $<3 \mathrm{~km}$ versus $<6 \mathrm{~km})$ than those 220 suggested by the strain field in the numerical models of Nikolinakou et al. (2014, see their figure 7). These differences may reflect variations in the country rock rheology and salt geometry through 222 time, and, in particular, the diapir radius which dictates fault length. 
Coleman et al., 2018 - How, where, and when do radial faults grow near salt diapirs? https://doi.org/10.1130/G40338.1

\section{ACKNOWLEDGMENTS}

225 We thank Investigação Petrolífera Limitada (PGS) for the provision of and permission to 226 publish seismic data, and Schlumberger for the provision of the Petrel software to Imperial College

227 London. Michael Hudec, Mark Rowan, Thilo Wrona, and Tim Dooley are thanked for their 228 valuable discussions. We thank editor Dennis Brown, as well as Katherine Giles, Ian Davison, 229 Stefano Tavani, and Martha Withjack for their constructive reviews that significantly improved 230 this manuscript. 
Coleman et al., 2018 - How, where, and when do radial faults grow near salt diapirs? https://doi.org/10.1130/G40338.1

\section{REFERENCES CITED}

Baudon, C., and Cartwright, J.A., 2008, 3D seismic characterisation of an array of blind normal faults in the Levant Basin, Eastern Mediterranean: Journal of Structural Geology, v. 30, p. 746-760, https://doi.org/10.1016/j.jsg.2007.12.008.

Bishop, R.S., 1978, Mechanism for emplacement of piercement diapirs: American Association of Petroleum Geologists Bulletin, v. 6, p. 1561-1583.

Carruthers, D., Cartwright, J., Jackson, M.P.A., and Schutjens, P., 2013, Origin and timing of layer-bound radial faulting around North Sea salt stocks: New insights into the evolving stress state around rising diapirs: Marine and Petroleum Geology, v. 48, p. 130-148, https://doi.org/10.1016/j.marpetgeo.2013.08.001.

Contreras, J., Zühlke, R., Bowman, S., and Bechstädt, T., 2010, Seismic stratigraphy and subsidence analysis of the southern Brazilian margin (Campos, Santos and Pelotas basins): Marine and Petroleum Geology, v. 27, p. 1952-1980, https://doi.org/10.1016/j.marpetgeo.2010.06.007.

Davison, I., Alsop, G.I., Evans, N.G., and Safaricz, M., 2000a, Overburden deformation patterns and mechanisms of salt diapir penetration in the Central Graben, North Sea: Marine and Petroleum Geology, v. 17, p. 601-618, https://doi.org/10.1016/S0264-8172(00)00011-8.

Davison, I., Alsop, I., Birch, P., Elders, C., Evans, N., Nicholson, H., Rorison, P., Wade, D., Woodward, J., and Young, M., 2000b, Geometry and late-stage structural evolution of Central Graben salt diapirs, North Sea: Marine and Petroleum Geology, v. 17, p. 499-522, https://doi.org/10.1016/S0264-8172(99)00068-9.

Davison, I., Anderson, L., and Nuttall, P., 2012, Salt deposition, loading and gravity drainage in the Campos and Santos salt basins, in Alsop, G.I., et al., eds., Salt Tectonics, Sediments and 
Coleman et al., 2018 - How, where, and when do radial faults grow near salt diapirs? https://doi.org/10.1130/G40338.1

Prospectivity: Geological Society of London Special Publications, v. 363, p. 159-174, https://doi.org/10.1144/SP363.8.

Demercian, S., Szatmari, P., and Cobbold, P.R., 1993, Style and pattern of salt diapirs due to thinskinned gravitational gliding, Campos and Santos basins, offshore Brazil: Tectonophysics, v. 228, p. 393-433, https://doi.org/10.1016/0040-1951(93)90351-J.

Dooley, T.P., Jackson, M.P., and Hudec, M.R., 2009, Inflation and deflation of deeply buried salt stocks during lateral shortening: Journal of Structural Geology, v. 31, p. 582-600, https://doi.org/10.1016/j.jsg.2009.03.013.

Giles, K.A., and Rowan, M.G., 2012, Concepts in halokinetic-sequence deformation and stratigraphy, in Alsop, G.I., et al., eds., Salt Tectonics, Sediments and Prospectivity: Geological Society of London Special Publications, v. 363, p. 7-31, https://doi.org/10.1144/SP363.2.

Jackson, C.A.-L., Jackson, M.P., and Hudec, M.R., 2015, Understanding the kinematics of saltbearing passive margins: A critical test of competing hypotheses for the origin of the Albian Gap, Santos Basin, offshore Brazil: Geological Society of America Bulletin, v. 127, p. 17301751, https://doi.org/10.1130/B31290.1.

Jackson, C.A.-L., Jackson, M.P.A., Hudec, M.R., and Rodriguez, C., 2014, Internal structure, kinematics, and growth of a salt wall: Insights from 3-D seismic data: Geology, v. 42, p. 307310, https://doi.org/10.1130/G34865.1.

Jackson, M.P., and Hudec, M.R., 2017, Salt Tectonics: Principles and Practice: Cambridge, UK, Cambridge University Press, 510 p., https://doi.org/10.1017/9781139003988.

Jones, I.F., and Davison, I., 2014, Seismic imaging in and around salt bodies: Interpretation (Tulsa), v. 2, p. SL1-SL20, https://doi.org/10.1190/INT-2014-0033.1. 
Coleman et al., 2018 - How, where, and when do radial faults grow near salt diapirs? https://doi.org/10.1130/G40338.1

277

278

279

280

281

282

283

284

285

286

287

288

289

290

291

292

293

294

295

296

Modica, C.J., and Brush, E.R., 2004, Postrift sequence stratigraphy, paleogeography, and fill history of the deep-water Santos Basin, offshore southeast Brazil: American Association of Petroleum Geologists Bulletin, v. 88, p. 923-945, https://doi.org/10.1306/01220403043.

Mohriak, W., Nemčok, M., and Enciso, G., 2008, South Atlantic divergent margin evolution: Riftborder uplift and salt tectonics in the basins of SE Brazil, in Pankhust, R.J., et al., eds., West Gondwana: Pre-Cenozoic Correlations Across the South Atlantic Region: Geological Society of London Special Publications, v. 294, p. 365-398, https://doi.org/10.1144/SP294.19.

Muraoka, H., and Kamata, H., 1983, Displacement distribution along minor fault traces: Journal of Structural Geology, v. 5, p. 483-495, https://doi.org/10.1016/0191-8141(83)90054-8.

Nikolinakou, M.A., Flemings, P.B., and Hudec, M.R., 2014, Modeling stress evolution around a rising salt diapir: Marine and Petroleum Geology, v. 51, p. 230-238, https://doi.org/10.1016/j.marpetgeo.2013.11.021.

Quintà, A., Tavani, S., and Roca, E., 2012, Fracture pattern analysis as a tool for constraining the interaction between regional and diapir-related stress fields: Poza de la Sal Diapir (Basque Pyrenees, Spain), in Alsop, G.I., et al., eds., Salt Tectonics, Sediments and Prospectivity: Geological Society of London Special Publications, v. 363, p. 521-532, https://doi.org/10.1144/SP363.25.

Withjack, M.O., and Scheiner, C., 1982, Fault patterns associated with domes-an experimental and analytical study: American Association of Petroleum Geologists Bulletin, v. 66, p. 302316. 
Coleman et al., 2018 - How, where, and when do radial faults grow near salt diapirs? https://doi.org/10.1130/G40338.1

\section{FIGURE CAPTIONS}

Figure 1. Radial fault formation via roof stretching (A) and stem push (B) with idealized fault throw-length plots. Radial fault $\mathrm{Y}$ throw increases toward the salt. Radial fault $\mathrm{X}$ does not encounter the salt. Red and blue units are tapered and tabular Composite Halokinetic Sequences (CHS; Giles and Rowan, 2012), respectively. C: Geographic context and variance (i.e., trace-totrace variability in acoustic impedance) slice at $1500 \mathrm{~ms}$ two-way time (TWT).

Figure 2. Seismic section showing the salt stock and stratigraphic position of horizons $\mathrm{H} 1-\mathrm{H} 3$ and packages A-C. Interpreted tapered Composite Halokinetic Sequences (CHS) in red, and tabular CHS in blue. CHS may exhibit different degrees of upturn next to the salt, forming cusps (inset). For location, see Figure 1C.

Figure 3. Variance map for horizons $\mathrm{H} 1-\mathrm{H} 3$, delineating radial faults and the salt. Throw maxima (white squares) for individual radial faults, throw-length plots for radial faults 1 and 2 (right), and the location of Figure 4 are also shown. For location, see Figure 1C. Throw maxima are absent for $\mathrm{H} 1$, as measured throw is at the limit of seismic resolution.

Figure 4. Seismic sections showing radial faults 3 (A) and 4 (B) with throw-depth profiles and expansion indices. Solid line is throw-depth, dashed line is expansion index. White circles are vertical fault tips, white squares are throw maxima. Radial fault 3 has a simple throw-depth profile with a single throw maximum. Radial fault 4 offsets older faults and has two throw maxima, indicative of dip linkage. See Figure 3 for location. 
FIGURE 1

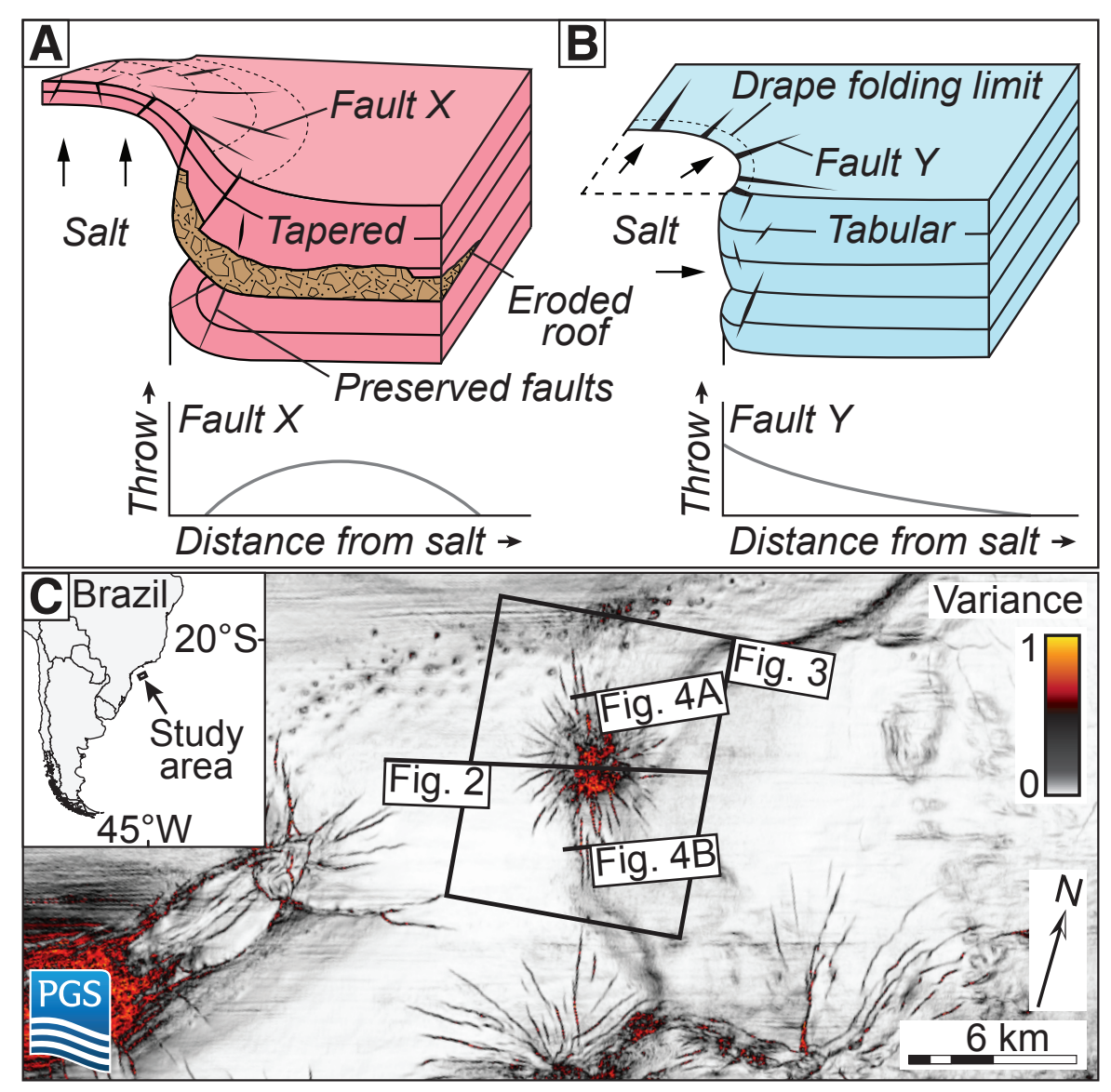




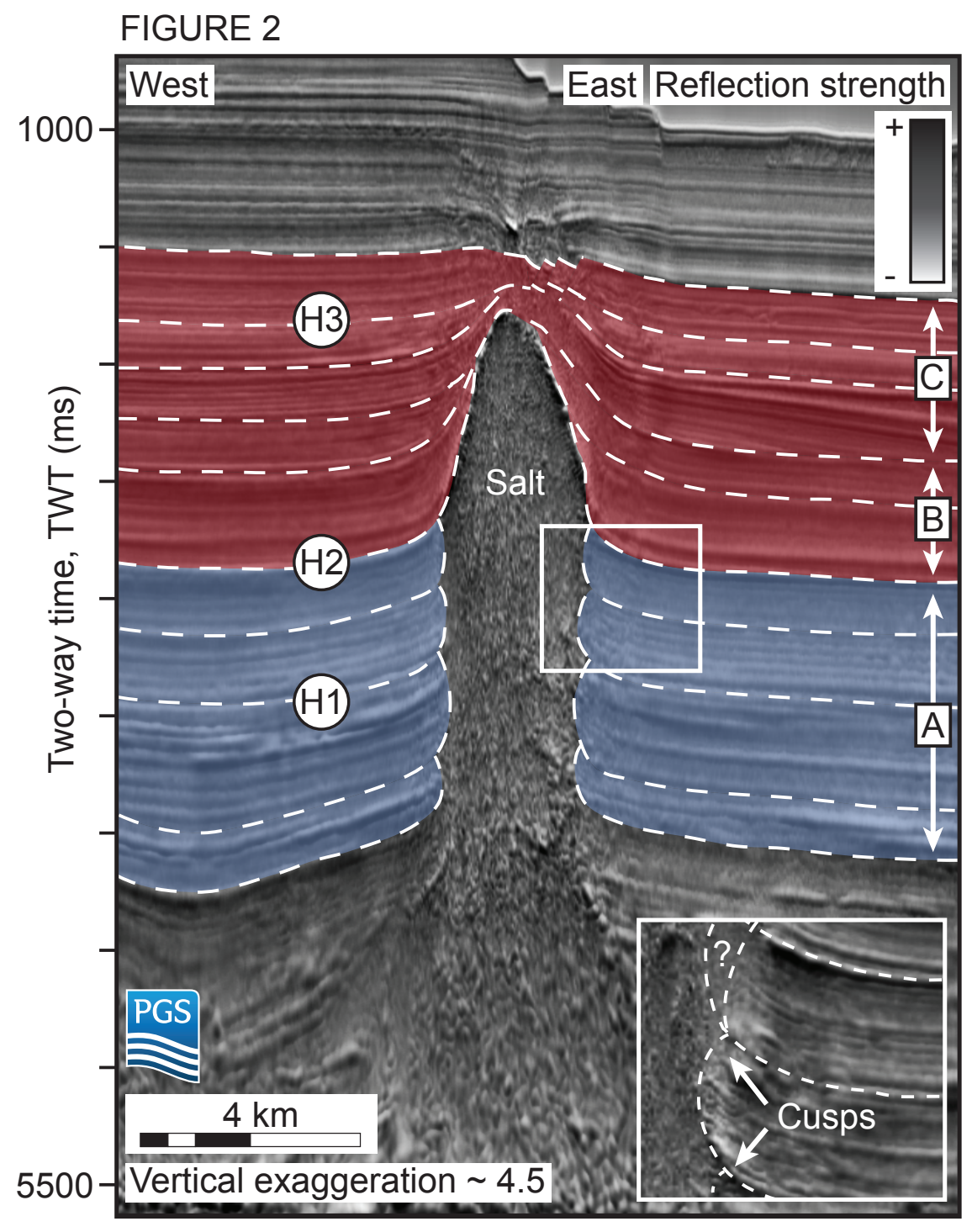




\section{FIGURE 3}
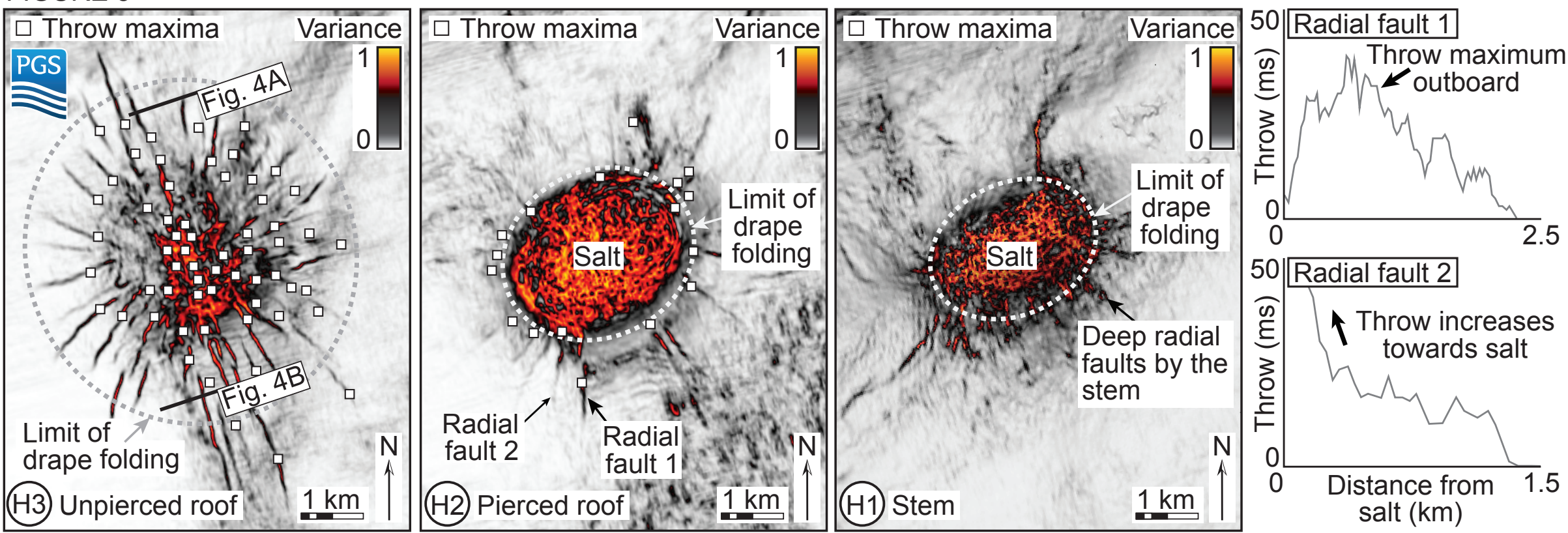
FIGURE 4

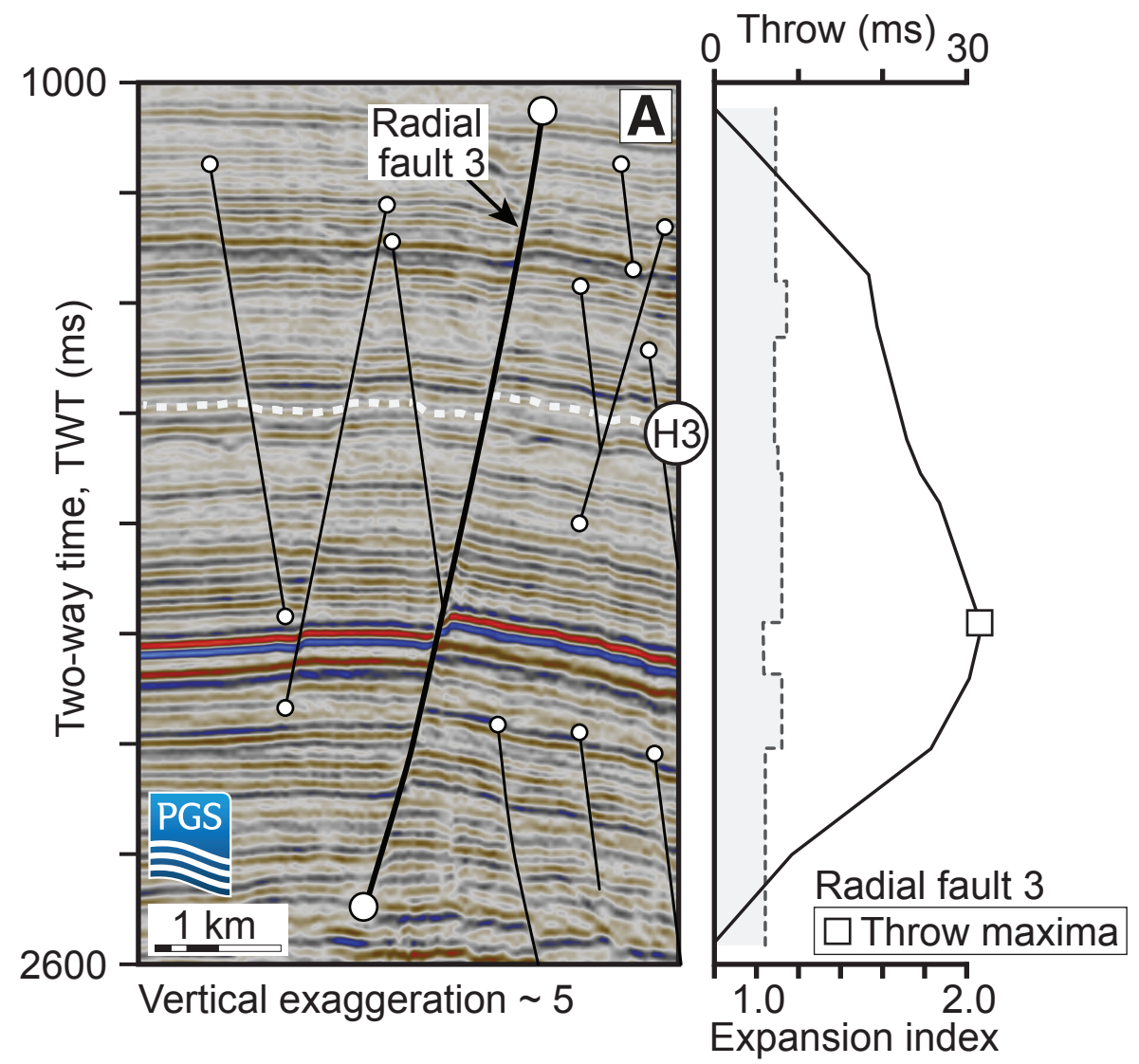

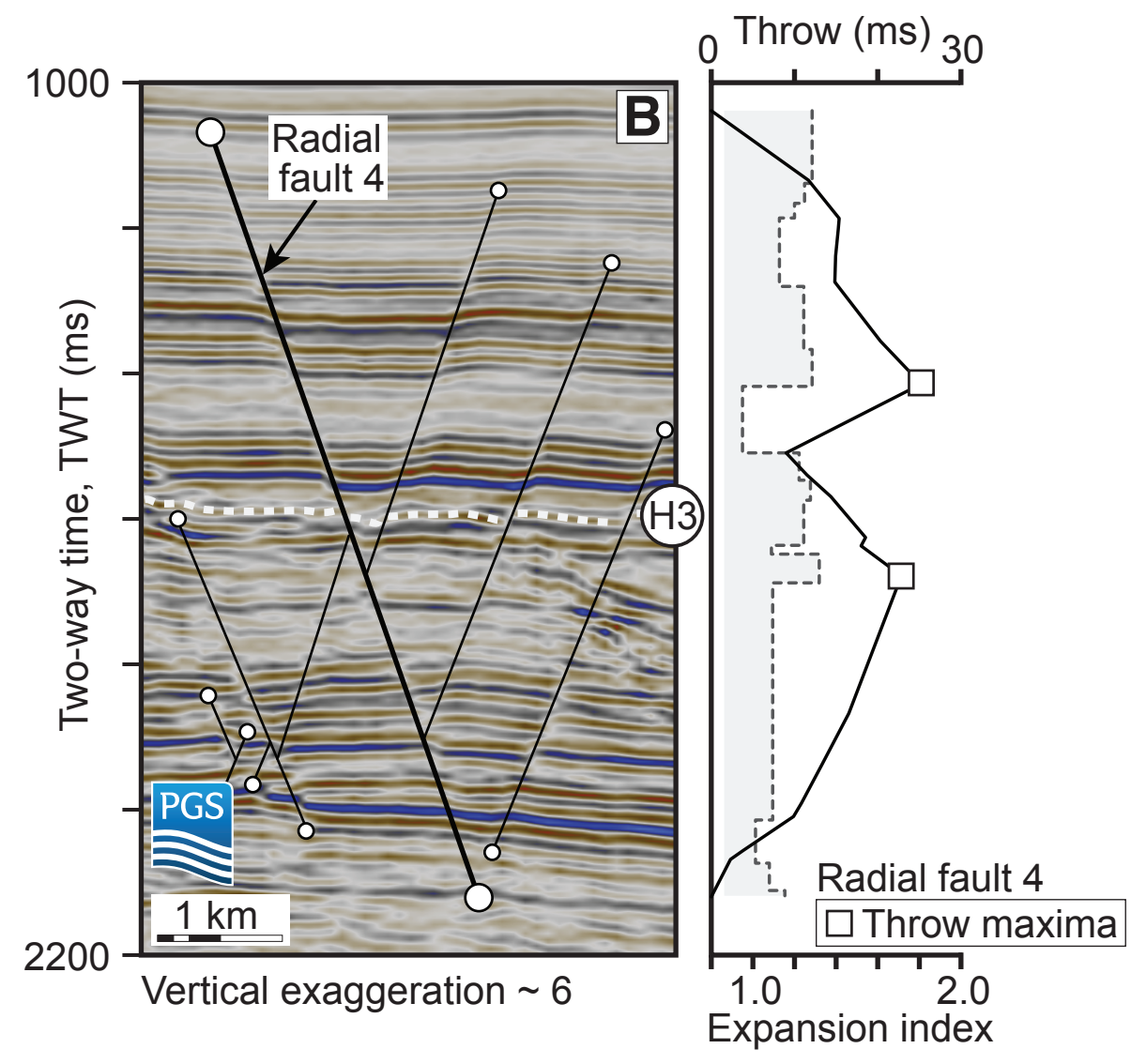




\section{APPENDIX 1. AVERAGE VERTICAL SEISMIC RESOLUTION}

Average vertical seismic resolution (red solid line) with depth using a velocity of $\sim 2 \mathrm{~km} / \mathrm{s}$ (after Jackson et al., 2014) and the frequency (black dashed line). The average vertical seismic resolution was calculated using the frequency and velocity. The instantaneous frequency is shown (left). Vertical exaggeration $\sim 4.5$.
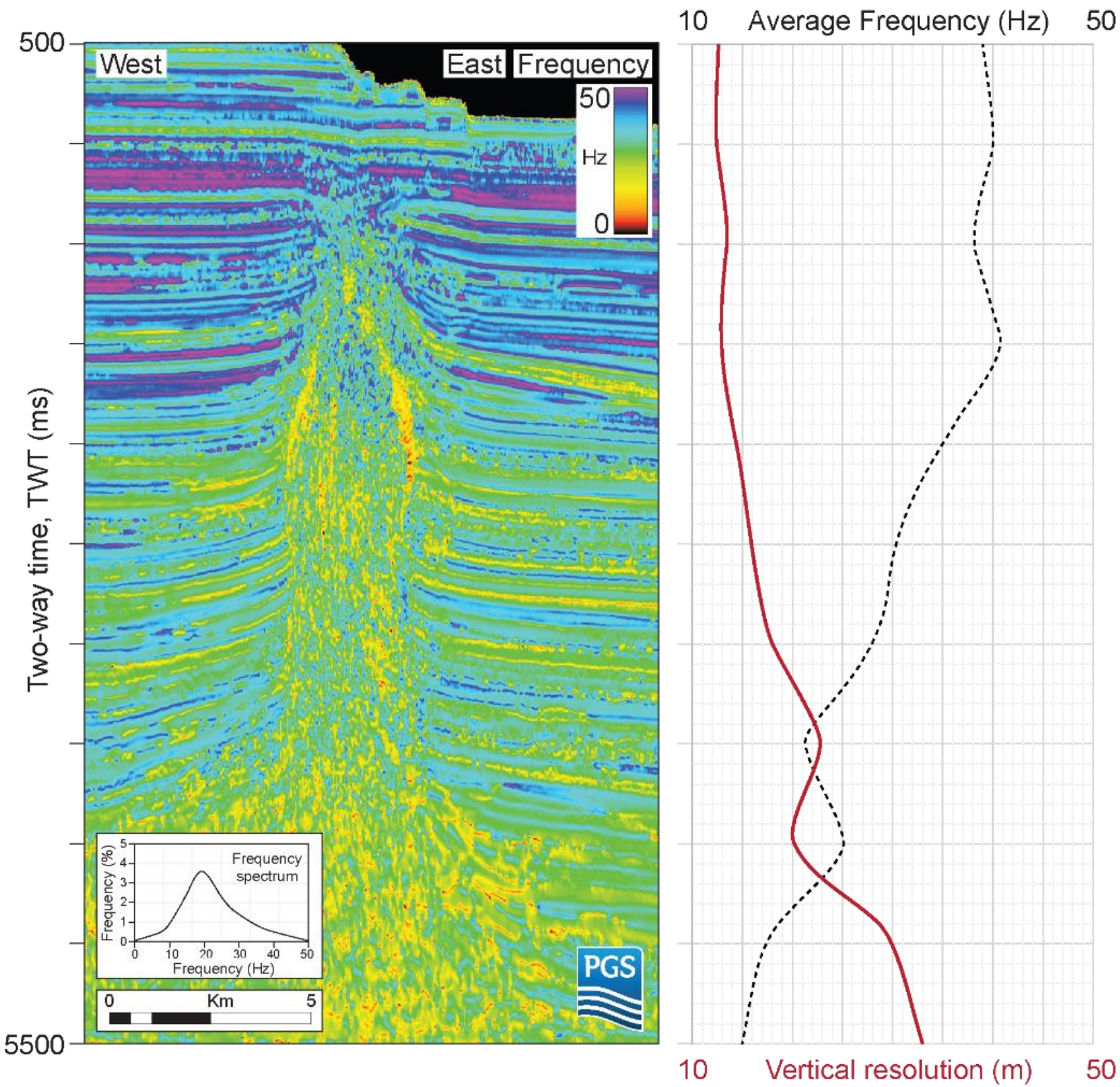


\section{APPENDIX 2. QUANTITATIVE THROW ANALYSIS METHOD}

Fault throw was measured perpendicular to radial fault strike every c. $50-100 \mathrm{~m}$ along the length of individual radial faults using horizon cut-offs (e.g. Muraoka and Kamata, 1983; Baudon and Cartwright, 2008). Cut-offs were defined using an extrapolated line that follows the regional trend of the chosen horizon prior to folding (Wilson et al., 2013), removing the effect of fault-parallel folding (Walsh et al., 1996). Therefore, total strain across the fault is accommodated, whether accommodated by ductile (continuous) or brittle (discontinuous) deformation (e.g. Long and Imber, 2010). The throw maxima was then identified on each radial fault, and plotted as white squares on Fig. 3. Fault throw was also measured with depth (T-z plots) using the aforementioned cut-offs, and throw maxima marked by white squares on Fig. 4.

Expansion indices illustrate variations in sediment thickness adjacent to fault systems, revealing the kinematics of bounding faults (e.g. Thorsen, 1963; Tvedt et al., 2013; Jackson et al., 2017). Expansion indices were calculated by dividing the hangingwall thickness of a stratal units by its corresponding footwall thickness and plotting these against geological time. An expansion index of 1 suggests no across-fault thickening, and a lack of syndepositional fault activity. An index of $>1$ suggests across-fault thickening and syndepositional fault activity. An index of $<1$ suggests stratal thinning from the footwall to the hangingwall, and may reflect difficulties in accurately measuring stratal thicknesses adjacent to a fault. Expansion indices near vertical fault tips may be slightly above and below one $( \pm 0.1)$ due to ductile deformation (e.g. Barnett et al., 1987). T1 - T4 represent horizon tops. The white circle represents the vertical fault tip. 

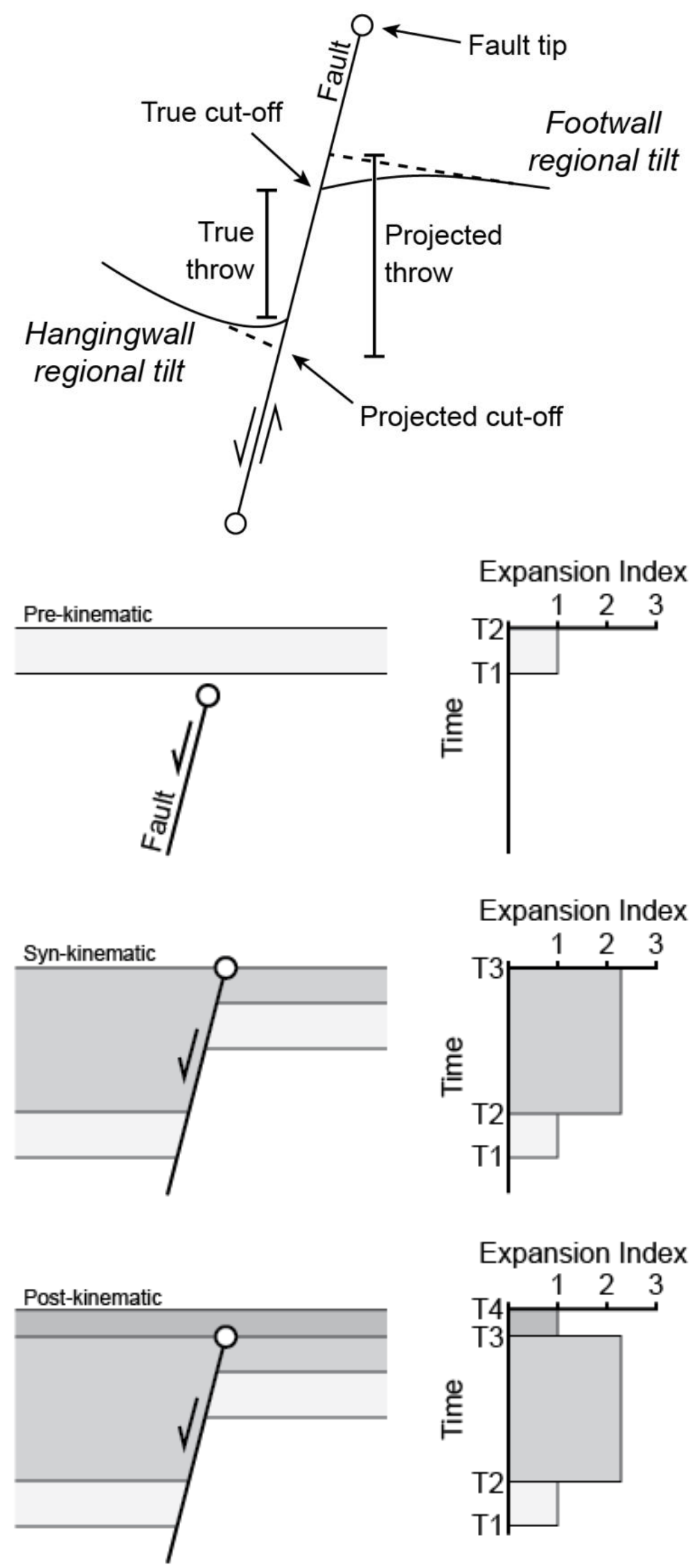


\section{References for Appendix 2}

Barnett, J. A., Mortimer, J., Rippon, J. H., Walsh, J. J., and Watterson, J., 1987, Displacement geometry in the volume containing a single normal fault: AAPG Bulletin, v. 71, no. 8, p. 925-937.

Baudon, C., and Cartwright, J. A., 2008, 3D seismic characterisation of an array of blind normal faults in the Levant Basin, Eastern Mediterranean: Journal of Structural Geology, v. 30, no. 6 , p. $746-760$.

Jackson, C. A.-L., Bell, R. E., Rotevatn, A., and Tvedt, A. B. M., 2017, Techniques to determine the kinematics of synsedimentary normal faults and implications for fault growth models: Geological Society, London, Special Publications, v. 439.

Long, J., and Imber, J., 2010, Geometrically coherent continuous deformation in the volume surrounding a seismically imaged normal fault-array: Journal of Structural Geology, v. 32, no. 2 , p. 222-234.

Muraoka, H., and Kamata, H., 1983, Displacement distribution along minor fault traces: Journal of Structural Geology, v. 5, no. 5, p. 483-495.

Thorsen, C. E., 1963, Age of growth faulting in southeast Louisiana.

Tvedt, A. B. M., Rotevatn, A., Jackson, C. A. L., Fossen, H., and Gawthorpe, R. L., 2013, Growth of normal faults in multilayer sequences: A 3D seismic case study from the Egersund Basin, Norwegian North Sea: Journal of Structural Geology, v. 55, p. 1-20.

Walsh, J. J., Watterson, J., Childs, C., and Nicol, A., 1996, Ductile strain effects in the analysis of seismic interpretations of normal fault systems: Geological Society, London, Special Publications, v. 99, no. 1, p. 27-40. 
Wilson, P., Elliott, G. M., Gawthorpe, R. L., Jackson, C. A.-L., Michelsen, L., and Sharp, I. R., 2013, Geometry and segmentation of an evaporite-detached normal fault array: 3D seismic analysis of the southern Bremstein Fault Complex, offshore mid-Norway: Journal of Structural Geology, v. 51, p. 74-91. 


\section{APPENDIX 3. FAULT THROW RESOLUTION}

Fault throw resolution for an example radial fault at Santos. Although vertical resolution may decrease with depth, the vertical offset between amplitude peaks between adjacent seismic traces permits fault throw to be measured to c. $5 \mathrm{~ms}$ at shallow depths $(<3000 \mathrm{~ms}$ TWT). However, at greater depths $(>3000 \mathrm{~ms}$ TWT $)$, the peaks of individual traces become increasingly smeared as the vertical resolution decreases, and as such, vertical offsets are less distinct and measurement becomes increasingly difficult.

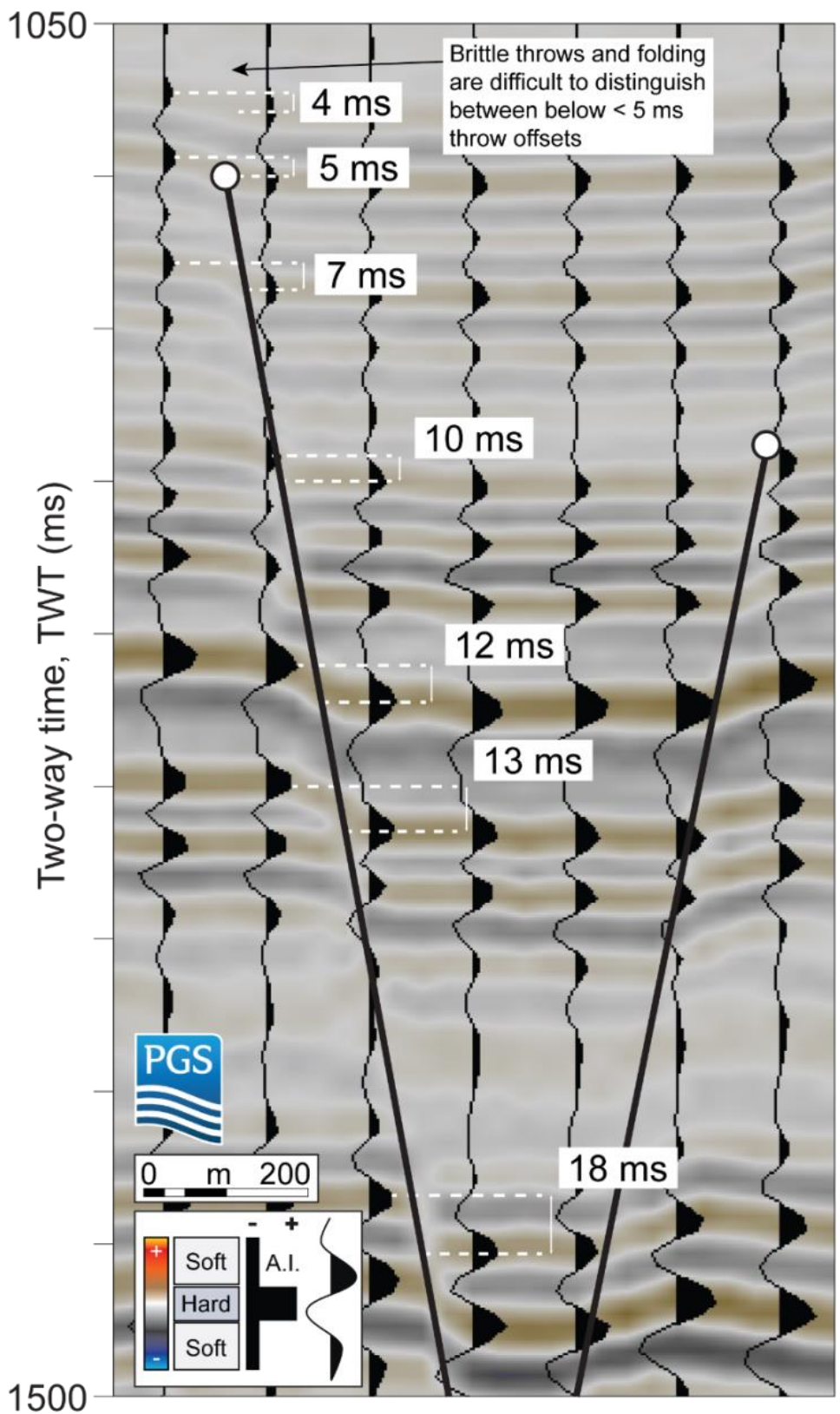




\section{APPENDIX 4. ASPECT RATIO FOR SANTOS BASIN RADIAL FAULTS}

Aspect ratios for Santos Basin radial faults. Velocity $\sim 2 \mathrm{~km} / \mathrm{s}$ after Jackson et al. (2014).

\begin{tabular}{|c|c|c|c|}
\hline Fault \# & Max Length (m) & Height (m) & Aspect Ratio \\
\hline 1 & 3727 & 871 & 4.28 \\
\hline 2 & 704 & 596 & 1.18 \\
\hline 3 & 639 & 639 & 0.69 \\
\hline 4 & 2021 & 811 & 2.49 \\
\hline 5 & 1340 & 809 & 1.66 \\
\hline 6 & 1131 & 655 & 1.73 \\
\hline 7 & 601 & 361 & 1.66 \\
\hline 8 & 2909 & 1521 & 1.91 \\
\hline 9 & 1075 & 434 & 2.48 \\
\hline 10 & 1732 & 650 & 2.66 \\
\hline 11 & 644 & 557 & 1.16 \\
\hline 12 & 1536 & 923 & 1.66 \\
\hline 13 & 833 & 833 & 0.72 \\
\hline 14 & 1542 & 620 & 2.49 \\
\hline 15 & 1826 & 683 & 2.67 \\
\hline 16 & 1100 & 208 & 5.29 \\
\hline 17 & 1742 & 666 & 2.62 \\
\hline 18 & 1322 & 500 & 2.64 \\
\hline 19 & 2001 & 736 & 2.72 \\
\hline 20 & 809 & 545 & 1.48 \\
\hline 21 & 579 & 579 & 0.78 \\
\hline 22 & 1246 & 275 & 4.53 \\
\hline 23 & 1969 & 501 & 3.93 \\
\hline 24 & 947 & 323 & 2.93 \\
\hline 25 & 2585 & 676 & 3.82 \\
\hline 26 & 882 & 735 & 1.20 \\
\hline 27 & 1726 & 669 & 2.58 \\
\hline 28 & 1490 & 731 & 2.04 \\
\hline 29 & 1713 & 368 & 4.65 \\
\hline 30 & 600 & 580 & 1.03 \\
\hline 31 & 1146 & 663 & 1.73 \\
\hline 32 & 644 & 579 & 1.11 \\
\hline 33 & 1471 & 782 & 1.88 \\
\hline 34 & 1004 & 350 & 2.87 \\
\hline 35 & 412 & 412 & 0.90 \\
\hline 36 & 754 & 496 & 1.52 \\
\hline 37 & 903 & 670 & 1.35 \\
\hline 38 & 2510 & 401 & 6.26 \\
\hline 39 & 1457 & 693 & 2.10 \\
\hline 40 & 464 & 464 & 0.82 \\
\hline 41 & 726 & 726 & 0.52 \\
\hline
\end{tabular}




$\begin{array}{lccc}42 & 540 & 540 & 0.92 \\ 43 & 955 & 685 & 1.39 \\ 44 & 856 & 657 & 1.30 \\ 45 & 1328 & 493 & 2.69 \\ 46 & 1072 & 734 & 1.46 \\ 47 & 791 & 726 & 1.09 \\ 48 & 1619 & 566 & 2.86 \\ 49 & 1580 & 551 & 2.87 \\ 50 & 1276 & 707 & 1.80 \\ 51 & 1288 & 463 & 2.78 \\ 52 & 859 & 701 & 1.23 \\ 53 & 1764 & 699 & 2.52 \\ 54 & 1090 & 480 & 2.27 \\ 55 & 964 & 596 & 1.62 \\ 56 & 754 & 754 & 0.88\end{array}$




\section{APPENDIX 5. CIRCUMFERENTIAL SEISMIC SECTIONS}

Circumferential seismic sections parallel to the salt-sediment interface documenting the different vertical tiers of radial faults around the isolated salt stock. H1 - 3 and Faults 1 - 4 are also shown.
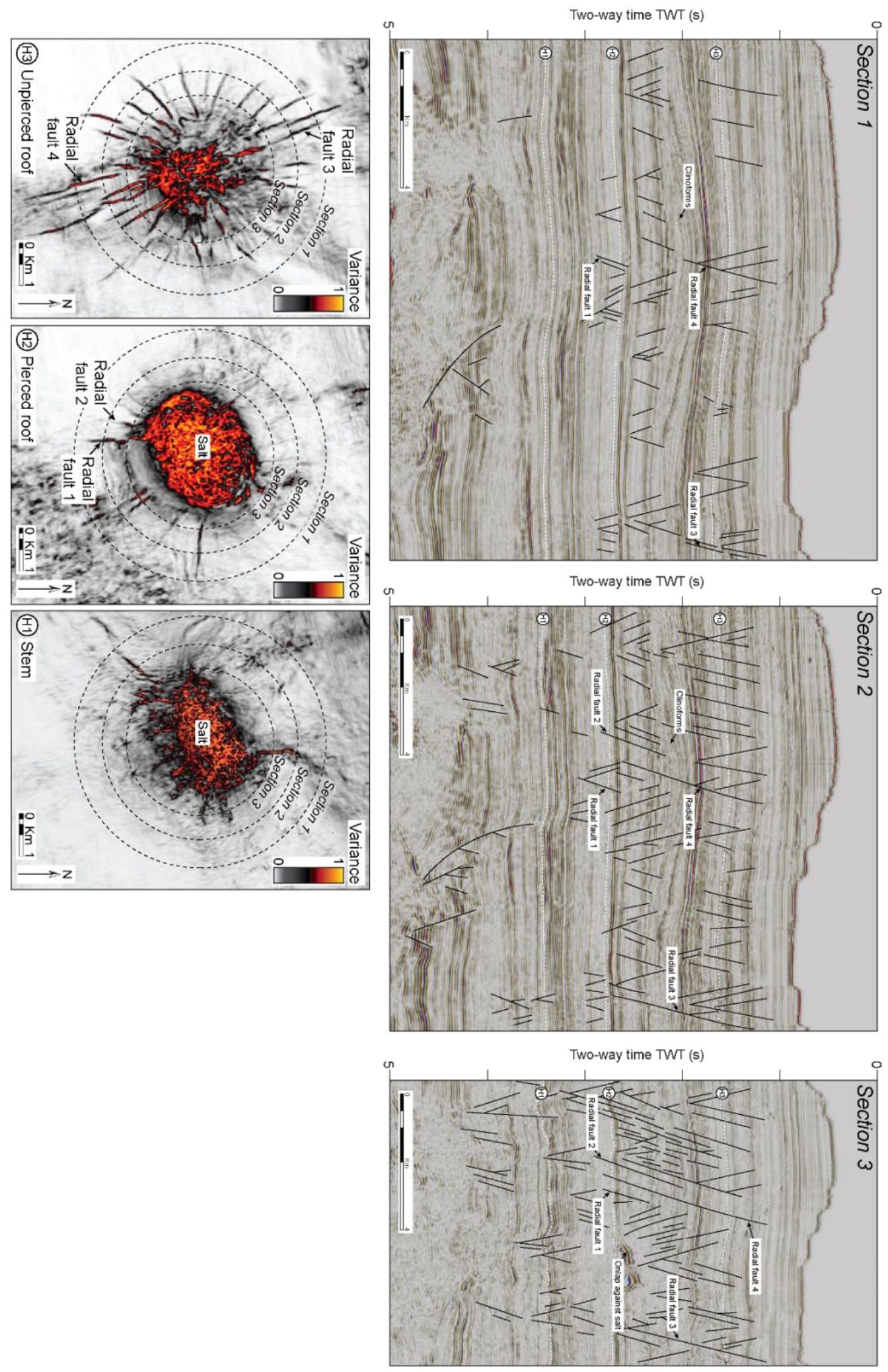


\section{APPENDIX 6. RADIAL FAULT THROW FOR H2-3}

Throw-distance on Fig. 3 used to determine the position of throw maxima along-strike for H2 - 3. Radial fault throw (i.e. strain) generally increases towards the diapir in $\mathrm{H} 1$ and $\mathrm{H} 2$.
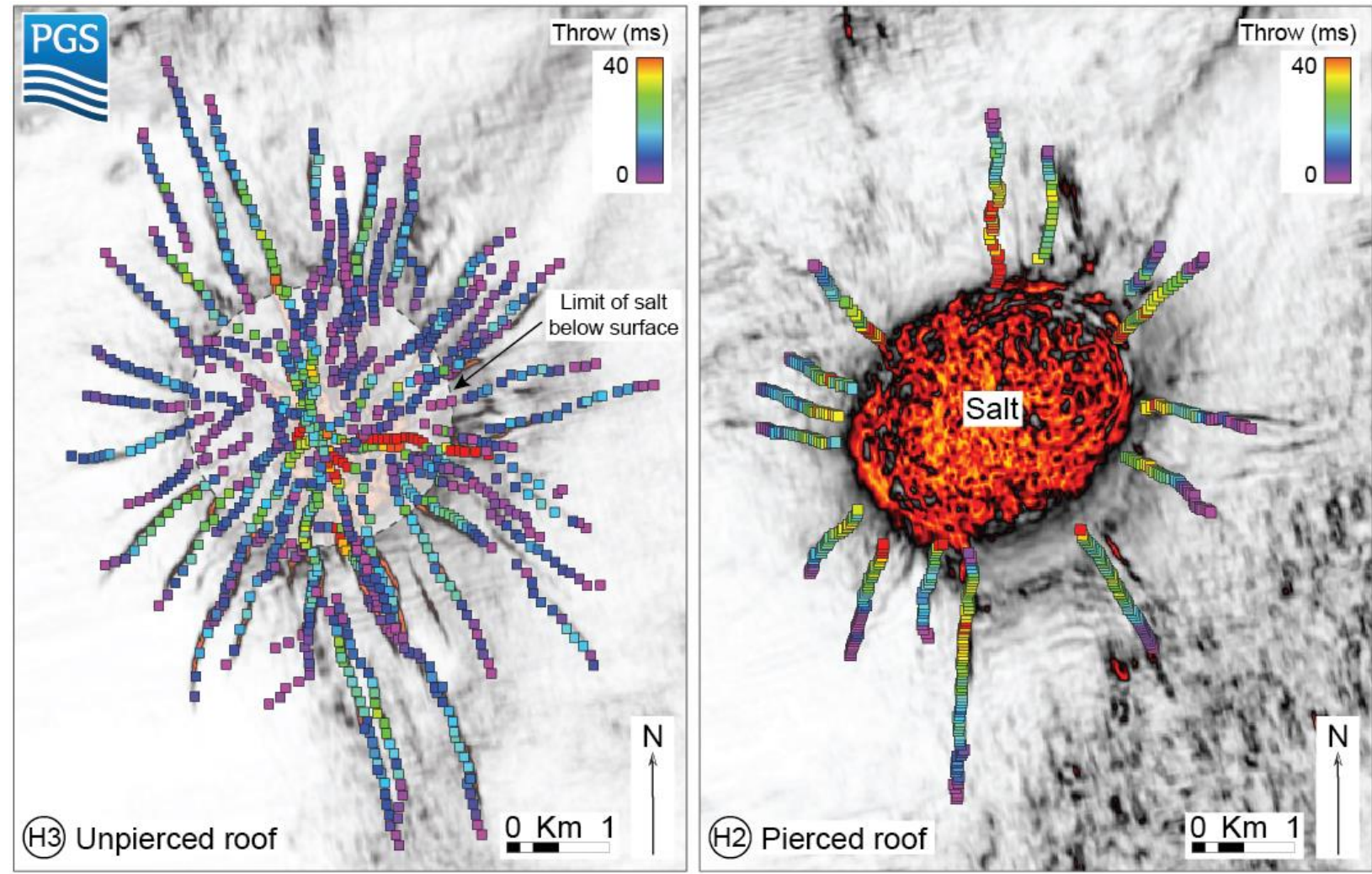


\section{APPENDIX 7. UPPER THROW TIP GRADIENTS}

Upper throw tip gradients for the Santos Basin radial faults.

\begin{tabular}{|c|c|c|c|}
\hline Fault & Throw (m) & Upper tip radius (m) & Vertical tip throw gradient \\
\hline 1 & 47 & 494 & 0.09 \\
\hline 2 & 32 & 308 & 0.10 \\
\hline 3 & 25 & 350 & 0.07 \\
\hline 4 & 25 & 281 & 0.09 \\
\hline 5 & 25 & 202 & 0.12 \\
\hline 6 & 20 & 139 & 0.14 \\
\hline 7 & 26 & 197 & 0.13 \\
\hline 8 & 23 & 499 & 0.05 \\
\hline 9 & 23 & 233 & 0.10 \\
\hline 10 & 21 & 303 & 0.07 \\
\hline 11 & 36 & 322 & 0.11 \\
\hline 12 & 37 & 507 & 0.07 \\
\hline 13 & 21 & 123 & 0.17 \\
\hline 14 & 16 & 151 & 0.11 \\
\hline 15 & 15 & 66 & 0.23 \\
\hline 16 & 29 & 254 & 0.11 \\
\hline 17 & 38 & 368 & 0.10 \\
\hline 18 & 30 & 307 & 0.10 \\
\hline 19 & 24 & 126 & 0.19 \\
\hline 20 & 20 & 338 & 0.06 \\
\hline 21 & 20 & 147 & 0.14 \\
\hline 22 & 20 & 305 & 0.07 \\
\hline 23 & 20 & 469 & 0.04 \\
\hline 24 & 20 & 454 & 0.04 \\
\hline
\end{tabular}




$\begin{array}{llll}25 & 66 & 515 & 0.13 \\ 26 & 60 & 499 & 0.12 \\ 27 & 22 & 125 & 0.18 \\ 28 & 22 & 206 & 0.11 \\ 29 & 23 & 310 & 0.07 \\ 30 & 22 & 427 & 0.05 \\ 31 & 21 & 312 & 0.07 \\ 32 & 19 & 231 & 0.08 \\ 33 & 19 & 194 & 0.10 \\ 34 & 22 & 396 & 0.06 \\ 35 & 24 & 250 & 0.09 \\ 36 & 21 & 335 & 0.06 \\ 37 & 14 & 284 & 0.05 \\ 38 & 18 & 247 & 0.07 \\ 39 & 21 & 248 & 0.08 \\ 40 & 18 & 337 & 0.05\end{array}$

